\title{
Ion Channel Pharmacology
}

\author{
Diana Conte Camerino, Domenico Tricarico, and Jean-François Desaphy
}

Pharmacology Division, Department of Pharmacobiology, School of Pharmacy, University of Bari, Bari, Italy

\begin{abstract}
Summary: Because ion channels are involved in many cellular processes, drugs acting on ion channels have long been used for the treatment of many diseases, especially those affecting electrically excitable tissues. The present review discusses the pharmacology of voltage-gated and neurotransmitter-gated ion channels involved in neurologic diseases, with emphasis on neurologic channelopathies. With the discovery of ion channelopathies, the therapeutic value of many basic drugs targeting ion channels has been confirmed. The understanding of the genotype-phenotype relationship has highlighted possible action mechanisms of other empirically used drugs. Moreover, other ion channels have been pinpointed as potential new drug targets. With regards to therapy of channelopathies, experimental investigations of the intimate drug-channel interac-
\end{abstract}

tions have demonstrated that channel mutations can either increase or decrease affinity for the drug, modifying its potential therapeutic effect. Together with the discovery of channel gene polymorphisms that may affect drug pharmacodynamics, these findings highlight the need for pharmacogenetic research to allow identification of drugs with more specific effects on channel isoforms or mutants, to increase efficacy and reduce side effects. With a greater understanding of channel genetics, structure, and function, together with the identification of novel primary and secondary channelopathies, the number of ion channel drugs for neurologic channelopathies will increase substantially. Key Words: Voltage-gated, neurotransmitter-gated, ion channel, drug therapy, channelopathy, pharmacogenetics.

\section{INTRODUCTION}

Ion channels are involved in many, if not all, cellular functions and are altered in many pathological conditions either indirectly or directly, as in the channelopathies. It is not surprising, therefore, that drugs targeting ion channels constitute important therapeutic interventions for a number of diseases. The use of ion channel modulators as drugs was operative long before their existence became known. Ion channel function is modulated by many natural agents of the animal and plant kingdoms, which contribute to the dangerous effects of poisons or the beneficial effects of medicinal herbs. Once isolated, these lead compounds have served as the basis for the synthesis of more specific ligands with fewer side effects. For instance, cocaine extracted from coca leaves entered clinical practice in the 1880 s for its analgesic properties, but the occurrence of CNS and cardiovascular toxicity led medicinal chemists to synthesize new derivatives, thus giving rise to the pharmaceutical class of local anesthetics, which are selective blockers of sodium

Address correspondence and reprint requests to: Diana Conte Camerino, Ph.D., Sezione di Farmacologia, Dipartimento FarmacoBiologico, Facoltà di Farmacia, Università degli Studi di Bari, via Orabona 4 - CAMPUS, I-70125, Bari, Italy. E-mail: conte@ farmbiol.uniba.it. channels. ${ }^{1}$ Beyond their usefulness in the clinical setting, natural ion channel ligands, especially toxins with high binding affinity, have also largely contributed to the discovery of the various ion channels and the understanding of their structure and function long before their molecular identification.

Historically, the role of ion channels was most obvious in the membrane of electrically excitable cells, such as the neuron, the cardiac myocyte, and the skeletal muscle fiber. Consequently, a number of drugs able to modulate cell excitability by acting on voltage-gated or neurotransmitter-gated ion channels in these tissues have reached blockbuster status in the pharmaceutical industry, generating large profits. Examples are the antiepileptic drugs (AEDs), which include blockers of voltage-gated sodium and calcium channels, agonists of $\mathrm{GABA}_{\mathrm{A}}$ receptors, and, more recently, openers of potassium channels and antagonists of AMPA and NMDA glutamate receptors.

Today more than 400 genes are known that encode even more ion channel subunits due to alternative splicing, each subunit being likely the target of many pharmacological agents. Covering all drugs acting on ion channels is beyond the scope of this review, which will instead focus mainly on drugs acting on ion channels involved in neurologic disorders and especially their use 
in channelopathies. The sections that follow each detail the pharmacology of an ion channel family. In addition, a synopsis of drug information for the neurologic channelopathies is provided in Table 1.

\section{PHARMACOLOGY OF POTASSIUM CHANNELS}

$\mathrm{K}^{+}$channels are classified on the basis of the primary amino acid sequence of the pore-containing unit ( $\alpha$-subunit) into three major families: 1) voltage-gated $\mathrm{K}^{+}$ channels $(\mathrm{Kv})$ containing six or seven transmembrane regions with a single pore, including also KCNQ, hERG, eag, and the $\mathrm{Ca}^{2+}$-activated $\mathrm{K}^{+}$channels; 2) inward rectifiers (Kir) containing only two transmembrane regions and a single pore; and 3) two-pore tandem $\mathrm{K}^{+}$ channels containing four transmembrane segments with two pores. The pore subunits coassemble with auxiliary subunits, affecting their pharmacological responses and modulation by second messengers.

\section{Pharmacology of voltage-gated potassium (Kv) channels}

Following the cloning of the four $\mathrm{K}^{+}$channel genes in Drosophila, several members of related voltage-gated $\mathrm{K}^{+}$ channel $(\mathrm{Kv})$ genes were identified in mammals and divided into eight gene families: KCNA (Kv1.1-8), KCNB (Kv2.1-2), KCNC (Kv3.1-4), KCND (Kv4.1-3), KCNF (Kv5.1), KCNG (Kv6.1-4), KCNS (Kv9.1-3) and KCNV (Kv8.1-3). The Kv1-4 families can form homoor heteromeric channels with other subunits from within their own family or with the electrically silent families (Kv5, Kv6, Kv8, and Kv9). The $\beta$-subunits of Kv channels influence channel properties, trafficking, and drug responses. $^{2}$

Kv1.1-2 channels are involved in neuronal channelopathies. Kv1.1 is expressed in many neurons, motor neurons, retina, and heart and skeletal muscle, whereas $\mathrm{Kv} 1.2$ is expressed mainly in the cerebellum, hippocampus, and thalamus. These low-voltage activated channels, located in the axons of neurons, do not affect the first action potential but increase the action potential threshold. ${ }^{3} \mathrm{Kv} 1.1$ and Kv1.2 can form heteromultimers important for repolarization of the presynapsis in neurons and skeletal muscle.

Loss-of-function mutations of KCNAl are associated with episodic ataxia type 1 (EA1), which is characterized by episodic failure of cerebellar excitation, while hyperexcitability of motor neurons is commonly observed. An imbalance between inhibitory and excitatory input in the cerebellum destabilizes motor controls during exercise and stress, leading to ataxias. ${ }^{2,4}$

Other neuronal Kv channels are the Kv3.1-2 controlling the release of GABA. These high-voltage activated channels participate to the repolarization of the postsynaptic action potential. ${ }^{2,3} \mathrm{Kv} 3.1^{-1-}$ mice show impaired motor skills and reduced muscle contraction force. Double Kv3.1/Kv3.3 knockout mice show ataxia, myoclonus, and other neurological abnormalities. $\mathrm{Kv}$ channels are also involved in neurological symptoms observed in paraneoplastic neurological syndromes, which are remote effects of cancer with an autoimmune response against CNS and peripheral nervous antigens. ${ }^{5}$ In neuromyotonia associated with limbic encephalitis and small cell lung cancer cells (SCLC), function of Kv1.1/Kv1.2 channels is progressively lost because of an abnormally enhanced turnover and degradation of the proteins. The immune system is also modulated by the Kv1.3 channel, which is expressed in many cells involved in immune responses and is a drug target. ${ }^{5}$

Kv channel blockers. The voltage-gated $\mathrm{K}^{+}$channels have been investigated through the use of peptide toxins from animals and plants, such as dendrototoxins, kalitoxin, hongotoxin, margatoxin, and others that block the channel pore at picomolar to nanomolar concentrations and serve as tools for the analysis of their structurefunction relationships. These toxins block Kv1.1-6 channel subtypes. ${ }^{2,6}$ Although $\mathrm{Kv}$ channels were the first to be molecularly characterized, no selective blockers or openers are currently available. Tetraethylammonium (TEA) and 4-aminopyridine (4-AP) are classic Kv channel blockers, which can discriminate between various channel subtypes. The Kv1.1, Kv3.1-4, and Kv7.2 channels are more sensitive to TEA. Kv1.1-5, Kv1.7 and Kv3.1-2 are inhibited by micromolar concentrations of 4-AP, but millimolar concentrations are needed to block $\mathrm{Kv} 1.6,1.8,2.2,3.3$ and $\mathrm{Kv} 4.1-3$.

Other members, such as Kv2.1, Kv3.4, hERG, eag1, and KCNQ channels, are insensitive to 4-AP. Several 4-AP analogs have been tested against Kv channels, and the order of potency as $\mathrm{Kv}$ inhibitors ranks as follows 3,4-DAP $>4$-AP $>3$-AP $>2$-AP. ${ }^{7}$ These drugs cause neuronal firing and release of neurotransmitters such as acetylcholine (ACh). Thus, 4-AP and 3,4-diaminopyridine (3,4-DAP) (EU/3/02/124) (25-60 mg/day) are effective in those conditions associated with loss or reduced quantal release of neurotransmitters such as episodic ataxias, myasthenia gravis (MG), LambertEaton myasthenic syndromes (LEMS), and degenerative cognitive disorders.

In episodic ataxias type 2 and 6 (EA2 and EA6) the drugs enhance the excitability of spinocerebellar axis that is compromised by gain-of-function mutations of the $\mathrm{Ca}(\mathrm{v}) 2.1$ calcium channel $\alpha$-subunit. They reduce attack frequency but not duration, suggesting different mechanisms for triggering and maintaining the attacks. ${ }^{8}$ These drugs may be also effective in migraine, which is often associated with ataxia. 
TABLE 1. Drugs acting on ion channels used in the neurologic channelopathies

\begin{tabular}{|c|c|c|c|}
\hline Neurologic channelopathy & Ion channel mutants & Clinically used drugs for neurological symptoms & Mechanism of action \\
\hline Myotonic syndromes & & Symptomatic treatment independent on genetic origin & \\
\hline Myotonia congenita & ClC-1 channel & LA (mexiletine, flecainide) & Use-dependent block of muscle sodium channels \\
\hline Generalized myotonia & Idem & CBZ, phenytoin & Idem \\
\hline $\begin{array}{l}\mathrm{K}+\text {-aggravated myotonias } \\
\text { Paramyotonia congenita }\end{array}$ & $\begin{array}{l}\text { Nav1.4 channel } \\
\text { Idem }\end{array}$ & $\mathrm{ACTZ}$ & ClC- 1 channel activation through $\mathrm{CA}$ inhibition, others \\
\hline \multicolumn{4}{|l|}{ Periodic paralyses (PP) } \\
\hline Hypokalemic PP type1 (hypoPP1) & $\mathrm{Ca}_{\mathrm{v}} 1.1$ channel & ACTZ, dichlorphenamide & Direct activation of muscle BK channels; $\mathrm{CA}$ inhibition \\
\hline Hypokalemic PP type 2 & $\mathrm{Na}_{\mathrm{v}} 1.4$ channel & $\begin{array}{l}\text { ACTZ, dichlorphenamide } \\
\text { Triamterene, spironolactone }\end{array}$ & $\begin{array}{l}\text { ACTZ may worsen paralysis in some patients } \\
\mathrm{K}^{+} \text {-sparing diuretics in patients worsened by ACTZ }\end{array}$ \\
\hline Hyperkalemic PP & Idem & $\begin{array}{l}\mathrm{K}^{+} \text {-loss diuretics (thiazides) } \\
\text { ACTZ, dichlorphenamide } \\
\text { Salbutamol, terbutaline }\end{array}$ & $\begin{array}{l}\text { Reduction of blood potassium levels } \\
\text { See hypoPP } 1 \\
\beta_{2} \text {-adrenoceptor agonists: } \mathrm{Na} / \mathrm{K} \text { pump activation }\end{array}$ \\
\hline Andersen-Tawil syndrome & Kir2.1 channel & ACTZ, dichlorphenamide & See hypoPP1 \\
\hline Congenital myasthenic syndromes & Muscle nAChR & $\begin{array}{l}\text { Pyridostigmine, physostigmine } \\
\text { Diaminopyridine, quinidine }\end{array}$ & $\begin{array}{l}\text { Inhibition of acetylcholinesterase enzyme } \\
\text { Block of presynaptic Kv channels leading to ACh release }\end{array}$ \\
\hline Episodic ataxia type 1 (EA1) & $\mathrm{K}_{\mathrm{v}} 1.1$ channel & $\begin{array}{l}\text { ACTZ } \\
\text { CBZ, phenytoin }\end{array}$ & $\begin{array}{l}\text { Possible activation of the presynaptic } \mathrm{BK} \text { ? } \\
\text { Prevention of convulsions by } \mathrm{Na}^{+} \text {channel blockade }\end{array}$ \\
\hline Episodic ataxia type 2 & $\mathrm{Ca}_{\mathrm{v}} 2.1$ channel & $\begin{array}{l}\text { ACTZ } \\
\text { AED (valproate) }\end{array}$ & $\begin{array}{l}\text { See EA1 } \\
\text { Sodium channel blockade; other targets }\end{array}$ \\
\hline Spinocerebellar ataxia 6 & Idem & ACTZ & See EA1 \\
\hline Familial hemiplegic migraine & Idem & ACTZ & See EA1 \\
\hline Partial epilepsies & & Symptomatic treatment independent on genetic origin & \\
\hline Nocturnal frontal lobe epilepsy & CNS nAChR & CBZ, oxcarbazepine, phenytoin & Sodium channel blockade \\
\hline (ADNFLE) & & lamotrigine, zonisamide, valproate & Sodium channel blockade, other targets \\
\hline & & phenobarbital & Positive allosteric $\mathrm{GABA}_{\mathrm{A}} \mathrm{R}$ modulator, other targets \\
\hline & & felbamate & Na channel blockade, NMDA receptor antagonist \\
\hline & & topiramate & Na channel blockade, KA/AMPA receptor antagonist \\
\hline & & gabapentin, pregabalin & HVA Ca channel blockade \\
\hline $\begin{array}{l}\text { Generalized epilepsies } \\
\text { (mutations in the same gene can }\end{array}$ & Nav1.1 channel & $\begin{array}{l}\text { Symptomatic treatment independent on genetic origin } \\
\text { Ethosuximide }\end{array}$ & Blockade of T-type $\mathrm{Ca}^{2+}$ channels \\
\hline result in different disorders, and a & Nav1.2 channel & Valproate, Zonisamide & Blockade of T-type $\mathrm{Ca}^{2+}$ channels, other targets \\
\hline same disorder can result from & Nav2.1 subunit & Benzodiazepines & Positive allosteric $\mathrm{GABA}_{\mathrm{A}} \mathrm{R}$ modulators \\
\hline mutations in different genes) & $\mathrm{GABA}_{\mathrm{A}} \mathrm{R}$ & Lamotrigine & HVA calcium channel blockade, other targets \\
\hline GEFS +, SMEI, BFNC, & KCNQ2/Q3 & Retigabine & KCNQ2/3 agonist \\
\hline Absence epilepsy & ClC-2 channel & Felbamate, topiramate & multiple ion channel targets \\
\hline Myoclonic epilepsy & & ACTZ, sulthiame & reduced neuronal firing through $\mathrm{CA}$ inhibition \\
\hline Hyperekplexia & GlyR & Benzodiazepines & Positive allosteric $\mathrm{GABA}_{\mathrm{A}} \mathrm{R}$ modulators \\
\hline Familial erythermialgia & $\mathrm{Na}_{\mathrm{v}} 1.7$ channel & LA (lidocaine, mexiletine) & Use-dependent block of nerve sodium channels \\
\hline Paraneoplastic channelopathies & $\begin{array}{l}\text { Auto-antibodies } \\
\text { Against }\end{array}$ & $\begin{array}{l}\text { Immunosuppressive therapy is effective. } \\
\text { Symptomatic therapy is available }\end{array}$ & \\
\hline Neuromyotonia & Kv1.1, Kv1.2 & CBZ, phenytoin & Sodium channel blockade \\
\hline LEMS & P/Q Ca channel & Diaminopiridines & Block of presynaptic Kv channels \\
\hline Myasthenia gravis & nAChR & Pyridostigmine, physostigmine & Inhibition of acetylcholinesterase enzyme \\
\hline
\end{tabular}

Abbreviations: LA: local anesthetics; nAChR: nicotinic acetylcholine receptor; GABA ${ }_{\mathrm{A}} \mathrm{R}$ : $\gamma$-aminobutyric acid receptor type A; GlyR: glycine receptor; HVA: high voltage activated; LEMS: Lambert-Eaton myasthenic syndrome; SMEI: severe myoclonic epilepsy of infancy; BFNC: Begnin familial neonatal convulsions (BFNC); GEFS +: Generalized epilepsy with febrile seizures; CA: carbonic anhydrase. 
The treatment of MG is generally based on the use of anticholinesterases, such as pyridostigmine, which work also in LEMS. ${ }^{9}$ Quinidine and 3,4-DAP are also effective in MG and LEMS, because they improve the release of ACh that is disrupted by the autoantibodies directed against motor nerve terminals. Inhibition of Kv1.3 by Kv blockers may also explain their efficacy in LEMS and MG. Indeed, immunosuppressive therapy is successful in the treatment of the neuronal paraneoplastic channelopathies, but not in other paraneoplastic neurological syndromes.

The Kv blockers are not effective in neuromyotonia, however, which is characterized by peripheral nerve hyperexcitability. Neuromyotonia responds to the AEDs carbamazepine, phenytoin, and pregabalin. Other nonselective Kv channel blockers include linopirdine, a KCNQ channel blocker that evokes quantal ACh release in the CNS; the antiarrhythmic drugs flecainide and bupivacaine $(100-250 \mu \mathrm{mol} / \mathrm{L})$; verapamil, nifedipine, nicardipine, diltiazem $(20-200 \mu \mathrm{mol} / \mathrm{L})$, all of them wellknown vasodilating and antiarrhythmic drugs; and riluzole (100-200 $\mu \mathrm{mol} / \mathrm{L})$, a neuroprotective agent used in treating amyotrophic lateral sclerosis.

The blocking of $\mathrm{Kv}$ channels by drugs, as observed in anorexigens and dopamine agonists, may cause vasoconstriction with an increased risk of pulmonary hypertension and valvular heart disease. A reduced expression of $\mathrm{Kv} 1.5$ and Kv2.1 is associated with chronic pulmonary hypertension in humans. ${ }^{10}$

Kv channel openers. No drugs are available that open either wild-type Kv1.1 or the Kv1.1 mutants responsible for EA1. The current therapy of EA1 is based on the use of acetazolamide (ACTZ) (trade name: Diamox; 250$500 \mathrm{mg} /$ day), a carbonic anhydrase inhibitor that relieves the kinesigenic attacks and corrects dystonia in humans. It is possible that ACTZ is effective in EA1 indirectly by ameliorating the neurotransmission in the cerebellum and spinal cord. ACTZ does not interact with Kv channels in heterologous expression systems, suggesting that its effect in EA1 is mediated by other factors. One possibility includes a direct interaction of ACTZ with neuronal BK channels that modulate neurotransmitter release in the CNS, thereby compensating for the lack of presynaptic $\mathrm{Kv}$ in EA1. ACTZ can indeed open skeletal muscle BK channels. ${ }^{11}$ It is noteworthy that the lack of BK channels produces cerebellar ataxia along with Purkinje cell dysfunction in mice.

Promising effects in EA1 can also be observed with KCNQ openers, such as retigabine (currently used as an anticonvulsant) and flupirtine (used as an analgesic), both of which are also effective in paroxysmal dystonia mutant mice. ${ }^{12}$ Convulsions in EA1 are controlled by carbamazepine and phenytoin (see discussion of sodium channel blockers, below).
Pharmacology of KCNQ, hERG, and eag1 channels

Other genes were found to encode different voltagedependent $\mathrm{K}^{+}$channels, which are KCNQ1-5 (Kv7.1-5) channels and $\mathrm{KCNH}(\mathrm{Kv10}-12)$, including eag1 KCNH1 (Kv10.1) and hERG KCNH2 (Kv11.1). ${ }^{2,6}$ The KCNQ2-5 channels are expressed in neurons, being responsible for the M-currents inhibited by ACh through the muscarinic receptors involved in the ACh-dependent postsynaptic depolarization. Combinations of KCNQ3 with $\mathrm{KCNQ} 2, \mathrm{KCNQ} 4$, or KCNQ5 give rise to various heteromeric channels that underlie these currents. Mutations in $K C N Q 2$ or $K C N Q 3$ result in a loss of function and an increase in cellular excitability, leading to benign familial neonatal convulsion. Mutations in KCNQ4 cause progressive hearing loss.

Because of their important physiological functions, KCNQ channels are potential drug targets. KCNQ1 and hERG are not involved in neuronal channelopathies, but have a physiopathological role in the heart. ${ }^{13}$ Indeed, drugs blocking these channels can precipitate long QT intervals, with potentially fatal effects. Eag1 is expressed in several brain areas and in skeletal muscle. $\mathrm{KCNH} 1$ is involved in the cell cycle and in cell proliferation. An abnormal expression is found in $70 \%$ of human cervical and breast carcinomas, so it is an oncogenic marker. No Eag1 blockers are available. ${ }^{6,13}$

KCNQ channel blockers. Interest in KCNQ channels was heightened by the observation that compounds developed as cognition enhancers, such as linopirdine and XE-991, are blockers of KCNQ channels. Blocking of $\mathrm{M}$-currents underlies the enhancement of transmitter release by these drugs. ${ }^{6}$ Linopirdine increases ACh release in rat brain and improves performance in animal models of learning and memory. Although clinical data with linopirdine were inconclusive, several analogs such as XE-991 and DMP-543 were developed as orally active ACh-releasing agents with potential in Alzheimer's disease. Heteromers derived from the cardiac KCNQ1/ minK are 14- to 18 -fold less sensitive to XE-991 blockade compared with either KCNQ1 alone or neuronal KCNQ2/3 combination, demonstrating selectivity of these compounds for neurotransmitter release over cardiac function. The compounds are 10 to 20 times more potent in releasing $\mathrm{ACh}$ from the hippocampus, with improved half-life and brain-plasma distribution compared with linopirdine. Compounds inhibiting M-currents selectively are potentially useful for treating cognitive deficits in neurodegenerative diseases and are likely to be forthcoming. These compounds are also promising drugs in the treatment of EA2, EA6, and LEMS.

KCNQ channel openers. These are the newest antiepileptic agents. The loss-of-function mutations in KCNQ channels associated with benign familial neonatal convulsions support the use of this class of drugs as 
antiepileptic agents. ${ }^{6,12}$ Retigabine, the desaza-analog of flupirtine (approved in Europe for general nociceptive pain), was originally identified as an anticonvulsant.

Retigabine is effective in various epilepsy models and was shown to activate $\mathrm{M}$-currents in various types of cultured neurons, suggesting KCNQ2/3 opening as a new mode of action for anticonvulsant drugs. The M-current is a slowly activating current whose threshold is near the resting potential. Retigabine shifts the activation of KCNQ M-current to more hyperpolarized membrane potentials, and also slows deactivation and accelerates activation, reducing neuronal firing. Retigabine acts on all neuronal KCNQ subunits, but not on the cardiac KCNQ1. A single 236-tryptophan residue within the S5 segment of KCNQ2 is critical for the effects of retigabine on gating and binding, and it is believed to be a part of a hydrophobic pocket when the channel opens. Retigabine enhances GABA-activated $\mathrm{Cl}^{-}$current at concentrations higher than those affecting KCNQ channels. The effect on $\mathrm{GABA}_{\mathrm{A}}$ receptors occurs independently of the benzodiazepine site. It is quite possible that this action may contribute, along with the effect on KCNQ channels, to the anticonvulsant activity of retigabine. It seems also likely that the effects on GABA may contribute to the dose-limiting CNS side effects that have occurred in clinical trials, including somnolence, dizziness, ataxia, confusion, speech disorder, vertigo, tremor, amnesia and abnormal thinking.

Analogs of retigabine with more favorable pharmacological profile are under investigation, including the benzanilide derivative ICA-27243 which is a more selective KCNQ opener and does not affect $\mathrm{GABA}_{\mathrm{A}}$ receptors or $\mathrm{Na}^{+}$channels. ${ }^{12}$ Retigabine has undergone Phase III clinical trial in patients with partial seizures with or without secondary generalization who were refractory to available therapies. Indications of efficacy were obtained in open-label trials with $35 \%$ to $44 \%$ of responders ( $\geq 50 \%$ reduction in seizure frequency). In a multicenter double-blind clinical trial, there was a dosedependent reduction in seizure frequency with a maximum responder rate of $33 \% .^{12}$

More recently, the anti-inflammatory drugs meclofenamate and diclofenac $(10-40 \mu \mathrm{mol} / \mathrm{L})$ were shown to be agonists of KCNQ2/3 channels. The effects of these drugs are KCNQ2/3 selective and synergic to retigabine, suggesting different sites of interaction. These drugs show anticonvulsant activity in vivo in maximal electroshock seizure (MES) tests. This may also contribute to their effects in migraine, neuropathic pain, and epilepsy. ${ }^{14}$ The antistroke agent BMS-204352 (trade name: Maxipost) is also a modulator of all neuronal KCNQ channels. ${ }^{15}$ The effect is stereoselective, because the $S$-enantiomer is an agonist and the $R$-enantiomer is an antagonist; both enantiomers are KCNQ1 antagonists.

\section{Pharmacology of calcium-activated potassium $\left(K_{\mathrm{Ca}}\right)$ channels}

Three subfamilies of $\mathrm{Ca}^{2+}$-activated $\mathrm{K}^{+}$channels can be distinguished. The first is the large conductance channels $\mathrm{K}_{\mathrm{Ca}} 1.1$ encoded by KCMNA1 (slo1) gene (BK) and the $\mathrm{K}_{\mathrm{Ca}} 4.1-2$ and $\mathrm{K}_{\mathrm{Ca}} 5.1$ channels, which are, however, less $\mathrm{Ca}^{2+}$ sensitive but activated by $\mathrm{Na}^{+}$and $\mathrm{OH}^{-}$ ions. ${ }^{16} \mathrm{BK}$ channels are widely expressed and are involved in hypertension, coronary artery spasm, urinary incontinence, stroke, psychoses, and several neurological disorders including epilepsy and schizophrenia. The second subfamily is the intermediate conductance $\mathrm{K}_{\mathrm{Ca}} 3.1$ encoded by the KCNN4 gene (IK), expressed in thymocytes, where it plays a role in immunostimulation and erythrocytes. This channel is also expressed in several cancer cell lines being involved in cell proliferation. The third of the subfamilies of calcium-activated potassium channels are the small conductance channels $\mathrm{K}_{\mathrm{Ca}} 2.1-3$ encoded by the KCNNI-3 genes (alias $h S K 1-3$ ), found in a variety of cells including sympathetic neurons, intestinal smooth muscle, bladder smooth muscle, hepatocytes, and brown adipocytes. In excitable cells, the SK channels are responsible for the slow after-hyperpolarization that follows action potential. Calmodulin is associated with the SK $\alpha$-subunit, and is necessary for $\mathrm{Ca}^{2+}$ binding and gating.

BK channel openers. These drugs stabilize the cell by increasing efflux of $\mathrm{K}^{+}$ions when the intracellular $\mathrm{Ca}^{2+}$ ions rise, leading to hyperpolarization and thus decrease of cell excitability. ${ }^{17}$ The BK channel has been more appealing as a therapeutic target than ATP-sensitive $\mathrm{K}^{+}$ channels $\left(\mathrm{K}_{\mathrm{ATP}}\right)$, because of the lower expression of BK channels in the heart. Furthermore, extensive $\mathrm{K}^{+}$efflux and a late channel opening (at approximately $0 \mathrm{mV}$ ) circumvent the adverse cardiac effects (hypotension, reflex tachycardia, and coronary artery steal) associated with $\mathrm{K}_{\mathrm{ATP}}$ openers.

The different subunit compositions of BK channels in various tissues open the possibility of finding tissueselective BK openers. In fact, the skeletal muscle BK is composed of the $\alpha$-subunit alone, the vascular BK is composed of $\alpha+\beta 1$, and the neuronal types of $\alpha+\beta 4$ or $\alpha+\beta 3$. These channels also show different responses to modulators. Peptide toxins can discriminate between peripheral BK formed by $\alpha$-subunit alone, which is sensitive to charybdotoxin (ChTX), and neuronal BK channels formed by $\alpha+\beta 4$ subunits, which is resistant to ChTX but sensitive to iberiotoxin (IbTX). Slotoxin, from a scorpion venom, selectively blocks $\alpha$-subunit of mammalian BK channels $\left(\mathrm{K}_{\mathrm{d}}=1.5 \mathrm{nmol} / \mathrm{L}\right)$ and can distinguish among $\alpha, \alpha+\beta 1$, and $\alpha+\beta 4$ more efficiently than can IbTX.

The BK openers comprise a large series of synthetic benzimidazolone derivatives such as NS004 and NS1619, biaryl amines, biarylureas, pyridyl amines, 3-aryloxin- 
doles, benzopyrans, dihydropyridines, and natural modulators such as dihydrosoyasaponin-1 (DHS-1) and flavonoids. Both NS004 and NS1619 are known as $\alpha$-subunit-selective BK openers. NS1619 is the only compound without any effects on other ion channels. The 3-fluoro aryloxindole analog BMS-204352 is neuroprotective and reduces infarct size in two rat stroke models. BMS-204352 has no effect on heart rate and mean arterial pressure in conscious dogs. In hippocampal slices it was able to reduce glutamate release $\left(\mathrm{IC}_{50}=352 \mathrm{nmol} /\right.$ L). BMS-204352 was well tolerated in phase I and II clinical trials, but failed to show efficacy against placebo as an antistroke agent in phase III clinical trials. Recently, BMS-204352 showed dose-related anxiolytic efficacy due to activation of KCNQ2-5 channels, and the $R$-enantiomer also activate $\mathrm{GABA}_{\mathrm{A}}$ receptor. ${ }^{15}$ It is likely that this drug would be of benefit in other disease conditions.

Other than benzimidazolone derivatives, a wide structural diversity of drugs showing BK activation properties has emerged. We have found that some carbonic anhydrase inhibitors increase $\mathrm{K}^{+}$currents in membrane patches isolated from muscle fibers by interacting with BK channels and their effects are structure-related. ${ }^{11}$ The order of potency as BK channel openers is ACTZ > bendroflumethiazide $>$ ethoxzolamide $>$ dichlorphenamide (DCP) (trade name: Daranide). Their action as BK channel openers is not correlated with the inhibition of the carbonic anhydrase enzymes. ACTZ and other carbonic anhydrase inhibitors are effective in preventing the insulin-induced paralysis and in restoring the serum $\mathrm{K}^{+}$ levels in $\mathrm{K}^{+}$-depleted rats, thus explaining their efficacy in hypokalemic periodic paralysis (hypoPP). ${ }^{18}$ ACTZ and DCP are indeed the first-line drugs in PP to reduce attack frequency and restore serum $\mathrm{K}^{+}$levels. ACTZ is effective in hypoPP type 1 , but efficacy in hypoPP type 2 is unclear. We have identified a BK channel in slow twitch muscle that is resistant to ACTZ. ${ }^{19}$

Various drugs such as niflumic, flufenamic, and mefenamic acids, as well as $17-\beta$ estradiol, activate BK channels in a nonselective manner. Channel activation by $17-\beta$ estradiol could contribute to its nongenomic effect on the vasculature (acute vasorelaxation). Tamoxifen, an estrogen receptor antagonist with mixed estrogenic properties, activates BK channels at therapeutic concentrations and blocks other ion channels such as $\mathrm{Kv}$ channels; this may explain the tamoxifen-induced QT prolongation and arrhythmias. ${ }^{17}$ An additive mechanism explaining the neuroprotection by BK openers may be the activation of the mitochondrial BK channels, which couple the intracellular $\mathrm{Ca}^{2+}$ levels to the electrical activity of the mitochondria. $^{20}$

BK channel blockers. Blockers of BK channels may have a role in those conditions associated with abnormal BK channel activity. ${ }^{13,17}$ Gain-of-function mutations of the KCMNA1 gene encoding the slo1 BK $\alpha$-subunit are linked to generalized epilepsy with dyskinesia. Abnormal function of the BK channels present in the presynaptic terminals affects the release of inhibitory neurotransmitters. The $\mathrm{Ca}^{2+}$ influx into the presynaptic terminal via voltage-gated $\mathrm{Ca}^{2+}$ channels initiates neurotransmitter release and activates presynaptic BK channels, which in turn terminates neurotransmitter release. Neuronal BK channels composed of a $\beta 3$-subunit variant $(\beta 3 \mathrm{~b}-\mathrm{V} 4)$ fail to terminate action potential and hence contribute to neuronal excitability observed in idiopathic epilepsy. Currently, no selective blockers are available for clinical use.

In this respect, the antiepileptic effects of carbonic anhydrase inhibitors including ACTZ, zonisamide, and sulthiame appear to be related to their ability to lower intracellular $\mathrm{pH}$ through inhibition of neuronal $\mathrm{CA}$ enzymes with reduction of the neuronal firing. ${ }^{21}$ Lowering of intracellular $\mathrm{pH}$ is known to inhibit several ion channels, including neuronal BK channels. Other unselective BK blockers are verapamil and gallopamil, which produce a flickering block of vascular BK channels. The anesthetic ketamine inhibits BK channels by an indirect mechanism. The antifungal clotrimazole inhibits BK activity, thereby increasing hormonal secretion and neuronal excitability.

IK channel blockers and openers. IK channel blockers may be of therapeutic interest for immunosuppressive therapy, through modulation of thymocytes and erythrocytes function. ${ }^{6}$ Nonselective IK blockers such as clotrimazole have shown antiproliferative effects on lymphocytes and cancer cell lines. Clinical evaluation of these drugs is underway.

IK channel openers may be beneficial in hypertension, cystic fibrosis, and peripheral vascular disease. Although not highly specific, 1-ethyl-2-benzimidazolinone (1-EBIO) and clinically used benzoxazoles are described as pharmacological activators of the IK channel. ${ }^{6}$

SK channel blockers and openers. SK channel blockers have been suggested for the treatment of myotonic muscular dystrophy, in which an abnormal activation of this channel has been found. They are also proposed in the treatment of gastrointestinal dysmotility, memory disorders, epilepsy, narcolepsy, and alcohol intoxication. Three classes of SKCa blockers are known: peptide toxins such as apamin and leiurotoxin I (scyllatoxin), bis-quinolinium blockers, and neuromuscular blockers such as tubocurarine. $^{6}$

SK channel openers may be important in diseases involving loss of synaptic plasticity, including age-related loss of memory and learning in Alzheimer's disease. $^{6}$ 


\section{Pharmacology of inward rectifier potassium (Kir) channels}

Since the initial cloning of the first inward rectifiers Kir1.1 (ROMK1) and Kir2.1 (IRK1), new members of this family have been identified, including the $G$ protein-coupled Kir3 and the ATP-sensitive Kir6. ${ }^{22}$ These channels play important roles in many organs including brain, heart, kidney, endocrine cells, ear, and retina. Seven Kir subfamilies are known: Kir1.1 (KCNJ1), Kir2.1-4 (KCNJ2,4,12,14), Kir3.1-4 (KCNJ6,5,9,3), Kir4.1-2 (KCNJ10,15), Kir5.1 (KCNJ16), Kir6.1-2 (KCNJ8,11), and Kir7.1 (KCNJ13). Kir2.1 is expressed in heart, skeletal muscle, and several brain areas, coassembling with other Kir2 to form functional channels. ATP opens Kir2 channels, possibly through phosphorylation by PKA or PIP2. Loss-of-function mutations of Kir2.1 are linked to Andersen's syndrome, which is a periodic paralysis associated with arrhythmias, dysmorphisms, $\mathrm{K}^{+}$homeostasis anomalies, and weakness.

$\mathrm{K}_{\text {ATP }}$ channels are octameric complexes of Kir6.1-2 and the sulfonylurea receptor subunits (SUR1, SUR2A, and SUR2B) with 1:1 stoichiometry. These channels are metabolically regulated and couple energy status of the cell with the membrane potential. $\mathrm{K}_{\mathrm{ATP}}$ channels are involved in several physiopathological processes involving glucose metabolism and heart contractility dysfunction. In skeletal muscle, a reduced activity of $\mathrm{K}_{\mathrm{ATP}}$ channels in human hypoPP patients carrying the R528H mutation of dihydropyridine receptor was found. Similarly, in $\mathrm{K}^{+}$-depleted rats a reduced expression or activity of the Kir6.2/SUR2A subunits was observed in fasttwitch muscles, suggesting a contribution of this channel to the hypoPP phenotype. Other Kir channels play a role in epithelial transport of $\mathrm{K}^{+}$ions such as the ROMK1, which is associated with the renal Bartter's syndrome characterized by hypokalemia. Kir3.1 (GIRK1) forms heteromeric channels with other members of the family, which are activated by $\mathrm{G}$ protein $(\mathrm{G} \beta \gamma$ subunit) and by PIP2.

$\mathbf{K}_{\text {ATP }}$ channel openers. Knowledge of the tissue-selective expression of various SUR subunits (SUR1, SUR2A-B) and Kir6.1-2 constituting $\mathrm{K}_{\mathrm{ATP}}$ channels has made possible the search for tissue-selective openers. ${ }^{23}$ The SUR subunits of $\mathrm{K}_{\mathrm{ATP}}$ channels are indeed the receptors for antagonists of the pancreatic channels, such as sulfonylureas (glibenclamide and tolbutamide) and glinides developed as antidiabetic drugs, and for the $\mathrm{K}^{+}$ channel openers $\left(\mathrm{KCO}-\mathrm{K}_{\mathrm{ATP}}\right)$ developed as antiangina, antihypertensive, and antihypoglycemic drugs. Firstgeneration $\mathrm{KCO}-\mathrm{K}_{\mathrm{ATP}}$ include benzopyrans (cromakalim), cyanoguanidines (pinacidil), thioformamides (aprikalim), thiadiazines (diazoxide), and pyridyl nitrates (nicorandil, minoxidil). Diazoxide activates the pancreatic Kir6.2/ SUR1 channel. The main cardiac and skeletal muscle Kir6.2/SUR2A complex is activated by cromakalim, and pinacidil, and cromakalim, diazoxide, nicorandil, mi- noxidil and pinacidil activate the vascular Kir6.1/SUR2B complex. However, the first-generation $\mathrm{KCO}-\mathrm{K}_{\mathrm{ATP}}$ have limited use, in that their lack of tissue selectivity contributes to side effects such as hypotension, tachycardia, hypertrichosis, and headache.

Second-generation KCOs synthesized include cyclobutenediones (WAY151616), 2H-1,4-benzoxazine derivatives, dihydropyridine-related structures (ZM244085), and tertiary carbinols (ZD6169), all showing enhanced potency and tissue selectivity. However, these compounds fail to show any advantage over other antihypertensive and antiasthmatic drugs in Phase III clinical trials. $^{23}$

$\mathrm{KCO}-\mathrm{K}_{\mathrm{ATP}}$ effects have been also investigated in neuromuscular disorders. Cromakalim repolarizes muscle fibers in hypoPP patients as well as in $\mathrm{K}^{+}$-depleted rats. A few experiments also show that this drug may, in vitro, suppress the abnormal myofiber hyperexcitability of myotonic patients. Furthermore, pinacidil is effective in reducing the attack frequency and in restoring muscle strength in hypoPP. ${ }^{24}$ Diazoxide was also found to ameliorate the weakness and paralysis in human hypoPP, possibly by opening skeletal muscle $\mathrm{K}_{\mathrm{ATP}}$ channels. These drugs hyperpolarize the sarcolemma when the ATP/ADP ratio increases, reducing $\mathrm{Ca}^{2+}$ influx and electrical activity. This has a beneficial effect on cellular energy saving. An additional mechanism has been proposed for diazoxide, which is also considered as a mito$\mathrm{K}_{\mathrm{ATP}}$ opener. It causes swelling, stimulation of respiration, inhibition of the MPTP pore, and $\mathrm{Ca}^{2+}$ overload reduction in mitochondria, thereby contributing to neuroprotection. ${ }^{25}$ However, first generation $\mathrm{KCO}-\mathrm{K}_{\mathrm{ATP}}$ are not skeletal muscle selective. New benzopyran derivatives, such as $2 \mathrm{H}$-1,4-benzoxazine analogs, have therefore been synthesized and tested on the muscular $\mathrm{K}_{\mathrm{ATP}}$ channels. $^{26}$ These compounds can open native $\mathrm{K}_{\mathrm{ATP}}$ channels in the nanomolar concentration range-showing however, a peculiar bell-shaped, dose-response curve that may limit their use in vivo.

Experiments are ongoing with new compounds to circumvent this problem. Recent findings that skeletal muscle, cardiac, and vascular tissues express SUR1 and SUR2B subunits, which are the high-affinity binding site for sulfonylureas, have toxicological implications. ${ }^{27}$ For example, the interaction of sulfonylureas with sarcolemmal $\mathrm{K}_{\mathrm{ATP}}$ channels enhances insulin sensitivity, contributing to the sulfonylurea-dependent hypoglycemia. Conversely, $\mathrm{KCO}-\mathrm{K}_{\mathrm{ATP}}$ may cause insulin resistance by reducing glucose uptake.

Kir channel openers. The pharmacology of Kir channels other than $\mathrm{K}_{\mathrm{ATP}}$ is not well defined. The therapy of Andersen's syndrome is symptomatic and aimed mainly at correcting the ventricular fibrillation and arrhythmias. $\mathrm{K}^{+}$-sparing diuretics such as triamterene and spironolactone are effective in this disorder, possibly by improving 
$\mathrm{K}^{+}$homeostasis. ACTZ may also be effective in Andersen's syndrome, through a mechanism as yet unknown. ACTZ may improve $\mathrm{K}^{+}$homeostasis, as observed with the $\mathrm{K}^{+}$sparing diuretics. Alternatively, the intracellular acidification due to CA inhibition by ACTZ may indirectly activate the cardiac $\mathrm{K}_{\mathrm{ATP}}$ with beneficial effect on the action potential. Other drugs possibly effective in this disorder are the cardiac KCO- $\mathrm{K}_{\mathrm{ATP}}$ openers, such as nicorandil and pinacidil, which may correct the lack of inward rectifier $\mathrm{K}^{+}$currents in cardiomyocytes and action potential prolongation. It is unlikely that the drug effects in Andersen's syndrome pass through activation of BK channels, which are not expressed in the heart.

$K_{\text {ATP }}$ and Kir channel blockers. $K_{\text {ATP }}$ channel blockers, such as sulfonylureas and glinides, are not in use in neuronal channelopathies. Kir channels are blocked by $\mathrm{Ba}^{2+}$ and $\mathrm{Cs}^{+}$ions and polyamines, which are of little therapeutic interest.

\section{Pharmacology of two-pore potassium channels}

The two-pore potassium ion channels (K2P) are responsible for the background $\mathrm{K}^{+}$conductance in the cells at rest. ${ }^{28}$ Fifteen mammalian genes belong to the KCNK family encoding the $\mathrm{K} 2 \mathrm{P}$ channels, including TASK1-3, TREK1-2, TRAAK, TWIK1-2, TALK1-2, and others. These are controlled by several stimuli, including oxygen tension, $\mathrm{pH}$, lipids, mechanical stretch, neurotransmitters, and $G$ protein-coupled receptors. These channels are also the targets for volatile and local anesthetics. TASK is involved in chemoreception; its inhibition by extracellular protons or hypoxia depolarizes the cells and starts the firing of respiratory motor neurons with increased frequency in the respiratory reflexes. TREK channels are expressed in neurons involved in thermoregulation. These are modulated by lipids and fatty acids. Volatile anesthetics open TREK channels, whereas local anesthetics block these channels. The fact that the neuroprotective agent riluzole is an activator of TREK raises the question as to whether it can be a drug target for neuroprotection.

\section{PHARMACOLOGY OF VOLTAGE-GATED CALCIUM $\left(\mathrm{CA}_{\mathrm{V}}\right)$ CHANNELS}

Ten different genes encode different $\alpha$-subunits composing the voltage-gated $\mathrm{Ca}^{2+}$ channels. ${ }^{29} \mathrm{Ca}_{\mathrm{v}} 1.1-4$ $\left(\alpha_{1 \mathrm{~S}}, \alpha_{1 \mathrm{C}}, \alpha_{1 \mathrm{D}}\right.$, and $\left.\alpha_{1 \mathrm{~F}}\right)$ mediate L-type $\mathrm{Ca}^{2+}$ currents; $\mathrm{Ca}_{\mathrm{v}} 2.1-3\left(\alpha_{1 \mathrm{~A}}, \alpha_{1 \mathrm{~B}}, \alpha_{1 \mathrm{E}}\right)$ mediate P/Q-type, N-type, and R-type $\mathrm{Ca}^{2+}$ currents, respectively; and $\mathrm{Ca}_{\mathrm{v}} 3.1-3\left(\alpha_{1 \mathrm{G}}\right.$, $\left.\alpha_{1 \mathrm{H}}, \alpha_{1 \mathrm{I}}\right)$ mediate T-type currents. The $\alpha$-subunits coassemble with $\alpha 2, \beta, \delta$, and $\gamma$ subunits to form functional channels in different tissues.

$\mathrm{Ca}_{\mathrm{V}} 1.1$ is the skeletal muscle isoform localized in the T-tubules participating in EC coupling. Loss-of-function mutations are associated with hypoPP type 1 in humans.
$\mathrm{Ca}_{\mathrm{V}} 1.2$ is the cardiac and smooth muscle isoform involved in EC coupling. It is found also in pancreatic $\beta$ cells, where it is involved in insulin secretion, and in the somatodendritic area of neurons. $\mathrm{Ca}_{\mathrm{V}} 1.3-4$ are the sensory isoforms localized in photoreceptors and cochlear cells, where they control neurotransmitter release, and in endocrine cells, neurons, and to lesser extent in cardiac cells, where they control cardiac rhythm. $\mathrm{Ca}_{\mathrm{v}} 2.1-3$ channels are linked to EA2, EA6, and migraine, disorders characterized by gain-of-function mutations of these channels in the cerebellum and spinal cord with neuronal atrophy and degeneration. $\mathrm{Ca}_{\mathrm{V}} 2.2$ is a neuronal channel involved in pain sensation and inflammation. $\mathrm{Ca}_{\mathrm{v}} 3$ channels are expressed in somatic and dendritic areas of neurons in the hippocampus, hypothalamus, thalamus, cerebellum, and cortex and are responsible for the Tcurrents. Abnormal openings of these channels are the basis for the low-frequency discharge $(3 \mathrm{~Hz})$ of the hypothalamic nucleus associated with absence epilepsy.

\section{$\mathrm{Ca}_{\mathrm{V}}$ 1.1-1.4 channel antagonists}

$\mathrm{Ca}_{\mathrm{V}}$ subunits have similar pharmacology and are targets of phenylalkylamines, dihydropyridines, and benzothiazepines, and are used as antihypertensive and antiarrhythmic drugs as previously described. ${ }^{29}$ The use of $\mathrm{Ca}^{2+}$ antagonists in the treatment of hypoPP patients was not successful.

\section{Ca $a_{v}$.1-3 channel antagonists}

$\mathrm{Ca}_{\mathrm{V}} 2.1-3$ channels are insensitive to classical $\mathrm{Ca}^{2+}$ antagonists, but are specifically blocked by high-affinity peptide toxins. Selective antagonists would be of benefit in EA2-6 and migraine disorders. Acetazolamide is the first-line treatment in EA2 (which is thus named acetazolamide-responsive ataxia) and can also help EA6 patients. The ACTZ effects in EA2-6 appear to be mediated by mechanisms not involving the P/Q type $\mathrm{Ca}^{2+}$ channels. ${ }^{30}$ It is likely that opening of presynaptic BK channels by ACTZ would buffer the P/Q mutant-dependent increase of presynaptic $\mathrm{Ca}^{2+}$ ion levels, thus controlling neurotransmitter release. In addition, inhibition of the R-type $\mathrm{Ca}^{2+}$ channel by ACTZ would reduce $\mathrm{Ca}^{2+}$ influx into the presynapsis. ${ }^{31}$ Blockers of $\mathrm{Ca}_{\mathrm{v}} 2.2$ channels have strong anti-inflammatory and analgesic effects comparable or superior to opiates. This channel is indeed the target of cannabinoids, opioids, neuropeptide $\mathrm{Y}$, and substance P. Intrathecal administration of ziconotide (trade name: Prialt), a synthetic analog of the $\omega$-conotoxin MVIIA, is effective in patients not responsive to opiates. Nonselective blockers of these channels are mibefradil, piperazines, gabapentin, and volatile anesthetics.

\section{$\mathrm{Ca}_{\mathrm{v}} 3$ channel antagonists}

$\mathrm{Ca}_{\mathrm{v}} 3$ channel antagonists are not related to drugs targeting others $\mathrm{Ca}^{2+}$ channels. ${ }^{29}$ Mibefradil is fairly selec- 
tive for T-type versus L-type $\mathrm{Ca}^{2+}$ currents, but was withdrawn from the market for its low pharmacotoxicological profile. The peptide kurtoxin inhibits activation gating of $\mathrm{Ca}_{\mathrm{v}} 3.1$ and $\mathrm{Ca}_{\mathrm{v}} 3.2$ channels. ${ }^{29}$ Other nonselective blockers are penfluridol, pimozide, amiloride, and phenytoin. More specific and high-affinity blockers of Cav3 channels would be useful for therapy. These channels are the main target of ethosuximide, widely used against absence seizures. Other AEDs with multiple modes of action, such as zonisamide (trade name: Zonigram) and valproate, can inhibit T-type $\mathrm{Ca}^{2+}$ channels. ${ }^{12}$

\section{PHARMACOLOGY OF VOLTAGE-GATED SODIUM CHANNELS}

The human genome contains nine genes encoding the main $\alpha$-subunit of voltage-gated $\mathrm{Na}^{+}$channels (SCN1A, $S C N 2 A$, and the rest) and at least four genes encoding auxiliary $\beta$-subunits ( $S C N 1 B$ to $S C N 4 B$ ), the expression of which is tissue-specific. Before the breakthroughs made with molecular genetics, the complexity of the $\mathrm{Na}^{+}$ channel repertoire was suggested by their different response to natural toxins. An initial distinction was made on the basis on their sensitivity to tetrodotoxin (TTX), a paralytic poison from some pufferfish. $\mathrm{Na}^{+}$channels were therefore divided into TTX-sensitive, which are expressed in the differentiated skeletal muscle and in central and peripheral neurons, and TTX-resistant, including the cardiac isoform and some subtypes expressed in peripheral nerves. Further distinction was possible with the use of $\mu$-conotoxins isolated from marine cone snails, which have a much higher affinity for skeletal muscle $\mathrm{Na}^{+}$channels than for neuronal channels.

At least eight distinct neurotoxin binding sites have been identified within the $\mathrm{Na}^{+}$channel protein, with different effects on ion permeation and gating resulting in either inhibition or enhancement of $\mathrm{Na}^{+}$currents. These toxins provide important tools for binding assays and definition of the channel structure-activity relationship. For instance, the activation of muscle $\mathrm{Na}^{+}$channels by the sea anemone toxin ATX II is used as a model for the biophysical and pharmacological characterization of sodium channel myotonia. ${ }^{32,33}$ Nonetheless, natural toxins have not found any therapeutic application, whereas synthetic $\mathrm{Na}^{+}$channel ligands have provided us with local anesthetics (LA), antiarrhythmics, and AEDs.

\section{Sodium channel blockers}

Because $\mathrm{Na}^{+}$channels are responsible for the upstroke and propagation of action potential in most excitable cells, drugs blocking $\mathrm{Na}^{+}$channels find application in a large spectrum of membrane hyperexcitability disorders, including cardiac arrhythmias, epilepsies, myotonias, and chronic pain. ${ }^{34}$ Many of these drugs are chemically related, and are grouped under the generic term local anesthetics, because they were first developed as alternatives to cocaine to obtain anesthesia and analgesia. ${ }^{1}$ Their cardioprotective effect was discovered later, leading to the birth of class I antiarrhythmics. Cardiac action of $\mathrm{Na}^{+}$channel blockers is discussed elsewhere in excellent reviews. ${ }^{35}$ Most clinical LAs have a tertiary amine associated with a hydrophobic aromatic ring through an amide or ester link. Experimental data suggest that the two ends of the drugs may interact with channel pore-lining amino acids through hydrophobic or $\pi$-cation interactions. ${ }^{36}$ Although antiepileptic $\mathrm{Na}^{+}$ channel blockers constitute a more heterogeneous chemical class, it is thought that their molecular receptor matches, at least partially, that of the LAs. ${ }^{36}$

Because the LA binding site lies within the $\mathrm{Na}^{+}$channel pore, both lipophilicity and pKa of the drugs are important determinants of channel block. At physiological $\mathrm{pH}$, LAs equilibrate between a liposoluble neutral form, which may reach or leave the receptor across the plasma membrane lipid phase even if the channel is closed, and a protonated form that needs channel opening to enter the pore and inhibit $\mathrm{Na}^{+}$currents in a usedependent manner. ${ }^{37}$ In addition, according to the modulated receptor hypothesis, the pore changes conformation during channel activity, thereby modifying the drug binding affinity as a function of channel state: the binding affinity of LA is far greater for open and inactivated sodium channels than for closed channels. Consequently, it is still a matter of debate whether the greater drug affinity for a specific $\mathrm{Na}^{+}$channel isoform with respect to others depends on subtle differences in the receptor site or differences in channel gating that secondarily affect receptor accessibility, or both.

The state-dependent affinity of drugs for $\mathrm{Na}^{+}$channels has two important implications for therapy. First, because the transition of the channel from the low-affinity closed state to the high-affinity open or inactivated state depends on membrane voltage, the drugs will blocks $\mathrm{Na}^{+}$channels in a voltage-dependent manner. Thus, the channel blocking will be greater in neurons than in skeletal muscle fibers or in an ischemic area than in healthy tissue. Second, channel block will increase with the frequency of stimulation, because the channel will spend more time in the open or inactivated states and the drug will have less time to dissociate from the channel between two action potentials. This frequency-dependent (or use-dependent) block is fundamental for the clinical use of LA drugs, allowing their selective action on hyperexcited tissues while preserving the normally functioning ones.

Use-dependent block is the basis for the use of LA in the treatment of myotonic syndromes, which are characterized by high-frequency action potential discharges in skeletal muscles. ${ }^{38}$ Currently, the preferred drug against myotonia is mexiletine, which is marketed as an antiar- 
rhythmic drug. More anecdotally, other $\mathrm{Na}^{+}$channel blockers used against myotonia include tocainide, procainamide, disopyramide, phenytoin, flecainide, and carbamazepine. There is, however, no controlled clinical trial available to confirm the efficacy and tolerability of drug treatment in myotonia. ${ }^{39}$

Mexiletine is administered in doses of 150 to $200 \mathrm{mg}$ two to three times a day and is generally well tolerated. Cardiac function and drug serum concentration should be carefully monitored, to reduce the risk of CNS and cardiac toxicity. The fact that mexiletine is useful in many patients suffering from either $\mathrm{Cl}^{-}$channel or $\mathrm{Na}^{+}$ channel myotonia, or even from myotonic dystrophy, suggests that mexiletine treatment is symptomatic. The drug, by blocking $\mathrm{Na}^{+}$channels, counteracts the hyperexcitability induced by the different genetic defects. In the case of $\mathrm{Na}^{+}$channel myotonias, however, the mutations themselves can modify the sensitivity of the channel to mexiletine. ${ }^{40-42}$ These modifications may result from altered intrinsic drug affinity or from mutationinduced altered gating that secondarily alters drug effect. Indeed, we proposed that the voltage-dependence of channel availability may be considered as a general index of mutant channel responsiveness to drug. ${ }^{41}$

The few mutations that shift this voltage-dependency toward more negative potentials increase mexiletine sensitivity, and the heterozygous patients may respond well to therapy, because of the preferential block of mutants with respect to wild-type channels. On the other hand, mutations that shift voltage-dependency toward more positive potentials reduce drug sensitivity; in this case, the mexiletine effect may be attributable to wild-type channel block, and patients may benefit from a drug having a more specific action on the mutant channel. On the way to defining a pharmacogenetic strategy to better address treatment in individual myotonic patients, we showed that flecainide may exhibit greater benefit in those patients carrying mutations with a positively shifted availability voltage-dependence. ${ }^{43}$

In isolated neurons, the inhibition of high-frequency action potential discharges by $\mathrm{Na}^{+}$channel blockers including phenytoin, carbamazepine, oxcarbazepine, lamotrigine, and valproate is obtained with drug concentrations similar to those able to produce an anticonvulsive effect in humans. These drugs are widely used in partial epilepsies and in symptomatic generalized tonic-clonic seizures. Lamotrigine and valproate are also efficient against absence seizures, most probably because they have multiple targets over $\mathrm{Na}^{+}$channels. Also, the glutamate antagonist AEDs, felbamate and topiramate, might block $\mathrm{Na}^{+}$channels. There is, however, no clear picture as to whether these drugs may be of benefit to patients with idiopathic epilepsy originating from a channelopathy.

Phenytoin and carbamazepine are used to control sei- zures in EA1, although $\mathrm{Na}^{+}$channel blockers may cause ataxia. Valproate, in combination with other AEDs, may be valuable in severe myoclonic epilepsy of infancy (SMEI), but lamotrigine may exacerbate seizures. This knowledge is based on physician experience, and molecular genetic approaches have as yet had little impact on SMEI therapy. ${ }^{44}$ Because SCN1A mutations may produce a loss of function of the $\mathrm{Na}^{+}$channel, ${ }^{45}$ it might appear reasonable to avoid treatment with $\mathrm{Na}^{+}$channel blockers in SMEI patients before a clear genotype-phenotype correlation has emerged.

As for $\mathrm{Na}^{+}$channel myotonias, there is also a possibility that $\mathrm{Na}^{+}$channel mutations in epilepsy may modify the AED effect. Recently, an epileptic mutation in the auxiliary $\beta_{1}$-subunit (mutation $\mathrm{C} 121 \mathrm{~W}$ in $S C N 1 B$ ) was shown to modify the voltage-dependence of a neuronal $\mathrm{Na}^{+}$channel $(S C N 3 A)$, consequently reducing the sensitivity of the mutant channel to phenytoin. ${ }^{46}$ Whether this finding is relevant for therapy remains to be verified. On the other hand, a recent study suggests that a common SCN1A polymorphism may influence the clinical use of phenytoin and carbamazepine, thereby supporting the usefulness of pharmacogenetics. ${ }^{47}$

Before its use in epilepsy, carbamazepine was originally approved in the United States for treatment of trigeminal neuralgia, a chronic pain syndrome. Other AEDs, such as phenytoin and lamotrigine, and some LA, such as lidocaine and mexiletine, were also found to be functional in the treatment of neuropathic pain in small cohorts of patients. It is believed that abnormal $\mathrm{Na}^{+}$ channel excitability of injured axons and their respective dorsal root ganglia neurons is a primary event in neuropathic pain. Recent findings strengthen this view, because a gain of function of the Nav1.7 channel expressed in nociceptors was shown to cause familial erythermalgia, an inherited pain syndrome linked to SCN9A mutations and responsive to lidocaine and mexiletine treatment, ${ }^{48,49}$ and an increased expression of the Nav1.3 channel was also found along the pain pathway after spinal cord injury. ${ }^{50}$ In addition, the up-regulation of TTX-resistant $\mathrm{Na}^{+}$channels induced by prostaglandins in nociceptors was recently pinpointed as the causal mechanism for the development of hyperalgesia in inflammatory pain. ${ }^{51}$ Although such a conclusion was recently challenged, ${ }^{52,53}$ with the increasing knowledge of $\mathrm{Na}^{+}$channel involvement in the various types of pain, the development of isoform-specific $\mathrm{Na}^{+}$channel blockers with greater efficiency and fewer side effects may represent a stimulating area in analgesia.

The tricyclic antidepressants are known to alleviate various pain syndromes, and $\mathrm{Na}^{+}$channel blockade by these drugs was proposed as the key mechanism for pain relief. For instance, the receptor for the tricyclic antidepressant amitriptyline overlaps with the LA receptor in $\mathrm{Na}^{+}$channels, and $\mathrm{Na}^{+}$channel blockade by amitrip- 
tyline conserves the hallmarks of LA action. ${ }^{54}$ It is noteworthy that tricyclic antidepressants such as imipramine, clomipramine, and amitriptyline have improved myotonia in patients with myotonic dystrophy. ${ }^{55}$

Sodium channel blockers are also increasingly studied for neuroprotection. ${ }^{56}$ Several very promising $\mathrm{Na}^{+}$channel blockers are in clinical trials for the acute treatment of cerebral stroke. $\mathrm{Na}^{+}$ions and channels may have an important role in the cascade of events leading to cell damage after global or focal ischemia in the brain, and many $\mathrm{Na}^{+}$channel blockers display considerable neuroprotective effects in models of ischemia. In amyotrophic lateral sclerosis, the only drug available today to reduce motor neuron damage is riluzole. Although this drug may have many molecular targets, it is thought that neuroprotection arises primarily from $\mathrm{Na}^{+}$channel blockade.

Other than the classical $\mathrm{Na}^{+}$channel blockers, a number of drugs acting primarily on other targets, as well as some dietary compounds, have been shown to block $\mathrm{Na}^{+}$ channels at relevant clinical concentrations. Recent examples include the antidepressant selective serotonin reuptake inhibitor, fluoxetine, and the red grape polyphenols, such as quercetin and resveratrol. ${ }^{57,58}$ Another example are drugs acting on $\beta_{2}$-adrenergic receptors, which are able to block $\mathrm{Na}^{+}$channels in a manner redundant to LA. ${ }^{59}$ Some $\beta_{2}$-adrenoceptor agonists have been used successfully to prevent attacks in hyperkalemic periodic paralysis patients, most probably by counteracting muscle membrane depolarization through activation of the electrogenic $\mathrm{Na}^{+} / \mathrm{K}^{+}$pump. Not all the $\beta_{2}$-agonists may be used in hyperPP patients, however, because the $\mathrm{Na}^{+}$channel block exerted by some of them (including clenbuterol) may accentuate the paralysis. Rather, we proposed the use of clenbuterol in patients suffering from myotonic dystrophy, because of the possibility of combining its well-known anabolic action with the antimyotonic activity through $\mathrm{Na}^{+}$channel use-de-

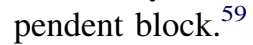

Empiric pharmacology has thus supplied us with a number of widely used drugs acting primarily as $\mathrm{Na}^{+}$ channel blockers. Current drugs have, however, a relatively low selectivity profile, acting equally on the various $\mathrm{Na}^{+}$channel subtypes. At present, the sole guarantee for safe use is provided by the voltage and use-dependent characteristics of $\mathrm{Na}^{+}$channel blockade. In the last decade, the discovery of sodium channelopathies has tremendously increased our knowledge of $\mathrm{Na}^{+}$channel involvement in pathological processes. In parallel, the elucidation of the intramolecular drug binding site provides an opportunity to understand the complex drugchannel interactions. These milestones promise the rapid development of pharmacogenetics, where old and new drugs which selectively affect specific $\mathrm{Na}^{+}$channel subtypes or mutants will be matched to specific diseases or even to specific mutations.

\section{Sodium channel activators}

The therapeutic use of $\mathrm{Na}^{+}$channel openers may seem inadvisable, because mutations resulting in a slight $\mathrm{Na}^{+}$ channel gain of function can induce membrane overexcitability in humans. Loss of function or expression of $\mathrm{Na}^{+}$channels has, however, been found to be associated with some sodium channelopathies leading to periodic paralysis, cardiac arrhythmia, and epilepsy. In these disorders, drugs that can promote $\mathrm{Na}^{+}$currents may be useful to restore normal excitability of affected tissue, but no such drug is currently available for therapy.

One promising possibility is the use of pharmacological chaperones, which are low molecular weight compounds that bind selectively to intracellularly retained proteins and promote their proper folding and membrane targeting. A number of genetic defects associated with epilepsy and cardiac arrhythmia impair $\mathrm{Na}^{+}$channel trafficking, resulting in haploinsufficiency. It has been shown that $\mathrm{Na}^{+}$channel ligands such as mexiletine can rescue mutant channels to the surface membrane. ${ }^{60} \mathrm{How}$ ever, a number of issues must be addressed before advancing to clinical trials in patients suffering from sodium channelopathies. For instance, drugs may be able to achieve channel rescue without blocking its activity and promote normal gating behavior of the rescued mutant channels. Alternatively, such agents could increase the expression of wild-type channels, which may counteract the haploinsufficiency due to retention of the allelic channel mutant (Desaphy and Conte Camerino, unpublished data).

\section{PHARMACOLOGY OF VOLTAGE-GATED CHLORIDE CHANNELS}

The voltage-gated chloride channels of the ClC family are encoded by nine different genes in mammals (CLCN1, CLCN2, and the rest). This family may serve as a paradigm for using human hereditary diseases and mouse models to facilitate the elucidation of the cellular roles of channels, whose function and even existence were still mysterious some 15 years ago. Myotonia congenita (MC) was the first human disease proven to be caused by an ion channel defect, thus leading to the discovery of the CLCN1 gene encoding the $\mathrm{ClC}-1$ channel responsible for the high $\mathrm{Cl}^{-}$conductance of skeletal muscle membrane. ${ }^{38,61}$ Chloride channel function is lost with MC mutations, thereby exacerbating muscle excitability and leading to abnormal myotonic runs of action potentials.

Human mutations in other $C L C N$ genes have been linked to idiopathic epilepsy, kidney diseases with or without deafness, and osteopetrosis. ${ }^{61}$ Indeed, these channels are expressed in the plasma membranes and in intracellular organelles of many tissues, where they perform a variety of functions including the regulation of 
cellular excitability, cell volume, transepithelial transport, and organelle acidification.

\section{Chloride channel blockers}

Much of the information regarding $\mathrm{ClC}$ channel pharmacology has been obtained by studying skeletal muscle $\mathrm{Cl}^{-}$conductance, leading to the identification of a series of blockers-which are, however, poorly selective, blocking many $\mathrm{Cl}^{-}$channels and transporters in various systems. ${ }^{62}$ Thus, more work is needed to develop $\mathrm{Cl}^{-}$ channel blockers with enough affinity and specificity for possible therapeutic use.

\section{Chloride channel openers}

To date, all mutations found in $C L C N$ genes produce a loss of function of the encoded $\mathrm{ClC}$ channel. The drugs of interest for chloride channelopathies should therefore be able to increase $\mathrm{Cl}^{-}$currents, a goal not yet achieved. ${ }^{62}$ The only exception is a bicyclic fatty acid, called lubiprostone, that selectively activates $\mathrm{ClC}-2$ channels. ${ }^{63}$ The U.S. Food and Drug Administration has recently approved lubiprostone (trade name: Amitiza) for the treatment of idiopathic chronic constipation. Identification of specific $\mathrm{ClC}$ channel openers would be useful for counteracting hyperexcitability in myotonia and epilepsy.

Another way to enhance $\mathrm{Cl}^{-}$currents is to indirectly increase $\mathrm{ClC}$ channel expression or function by stimulating intracellular biochemical pathways. For instance, muscle $\mathrm{Cl}^{-}$conductance increases in vivo and in vitro after application of insulin-like growth factor-1 or taurine ${ }^{64,65}$ Chronic treatment with taurine may improve myotonia. ${ }^{55}$ More recently, ACTZ, used as an alternative drug in myotonia, was shown to increase $\mathrm{ClC}-1$ channel currents in a mammalian cell line, most probably through intracellular acidification. ${ }^{66}$ We have also observed that ACTZ was able to improve function of a myotonia congenital $\mathrm{Cl}^{-}$channel mutant. ${ }^{67}$ Thus, the indirect activation of wild-type and mutant ClC- 1 channels by ACTZ might contribute to its therapeutic effects in muscle disorders.

\section{PHARMACOLOGY OF NEUROTRANSMITTER- GATED CHLORIDE CHANNELS}

The $\gamma$-aminobutyric acid and glycine receptors $\left(\mathrm{GABA}_{\mathrm{A}} \mathrm{R}\right.$ and GlyR) are the major inhibitory neurotransmitter-gated receptors in the CNS. ${ }^{68,69}$ Both receptors are pentameric, formed from subunits produced by different genes or splice variants, or both. After neurotransmitter binding, the ingress of $\mathrm{Cl}^{-}$ions within the cell hyperpolarizes the postsynaptic membrane, resulting in neurotransmission inhibition. Both receptors can be gated also by taurine. Dysfunction of GlyR and $\mathrm{GABA}_{\mathrm{A}} \mathrm{R}$ have been implicated in various channelopathies. GlyR mutations induce spasticity in mice and hy- perekplexia in humans, and $\mathrm{GABA}_{\mathrm{A}} \mathrm{R}$ mutations have been linked to idiopathic generalized epilepsy and Angelman's syndrome, a disorder characterized by severe mental retardation, convulsions, and delayed motor development. $^{45}$

The GlyR has a very modest pharmacological profile, and no therapeutic ligands are currently available. ${ }^{68}$ The loss of GlyR function due to mutations suggests, however, that selective GlyR agonists may find therapeutic application in diseases characterized by a lack of motor control.

Compared with GlyR, the drugs acting on $\mathrm{GABA}_{\mathrm{A}} \mathrm{R}$ encompass a broad therapeutic field, including anxiety, epilepsy, mood disorders, sleep disorders, schizophrenia, cognitive disorders, and general anesthesia. ${ }^{69}$ Drug affinity depends on receptor subunit composition, thereby offering a chance to develop $\mathrm{GABA}_{\mathrm{A}} \mathrm{R}$ subtype-specific drugs. For instance, the $\beta 3$ subunit of $\mathrm{GABA}_{\mathrm{A}} \mathrm{R}$ may be important for promoting sleep, because a mutation in this subunit was found in a patient with chronic insomnia and $\beta 3$ subunit knockout mice are insensitive to oleamide, an endogenous fatty acid sleep promoter. Thus, finding drugs acting preferentially on $\beta 3$ subunit-containing $\mathrm{GABA}_{\mathrm{A}} \mathrm{R}$ may be useful in the treatment of insomnia.

Positive allosteric $\mathrm{GABA}_{\mathrm{A}} \mathrm{R}$ modulators, such as phenobarbital and the benzodiazepines (diazepam, clonazepam, lorazepam, and the like), are widely used in the treatment of partial and generalized epilepsies. Mutations found in $\alpha 1$ and $\gamma 2$ subunits of GABA $_{\mathrm{A}} \mathrm{R}$ associated with epilepsy result in diminished synaptic inhibition, providing an explanation for the increased propensity to convulsions. Benzodiazepines may thus be particularly indicated in patients carrying $\mathrm{GABA}_{\mathrm{A}} \mathrm{R}$ mutations. Some mutations, however, may also impair $\mathrm{GABA}_{\mathrm{A}} \mathrm{R}$ expression or benzodiazepine responsiveness, which theoretically may hamper their use in these patients. Clearly, more studies are needed to allow a pharmacogenetic approach to epileptic $\mathrm{GABA}_{\mathrm{A}} \mathrm{R}$ channelopathies. ${ }^{44}$

\section{PHARMACOLOGY OF NEUROTRANSMITTER- GATED CATIONIC CHANNELS}

Neurotransmitter-gated cationic channels include nicotinic ACh receptors, glutamate receptors, and serotoninergic receptors. The nicotinic receptor channels are expressed in the neuromuscular plaque, the noradrenergic and cholinergic ganglions, and the CNS. Several nicotinic receptor subtypes are known to show different pharmacological responses to drugs and toxins. Although loss-of-function mutations of nicotinic receptors are involved in MG and epilepsy, no drugs are known that are capable of restoring normal channel function. The drugs and toxins targeting nicotinic receptors are instead used as ganglioplegic and muscle relaxants in anesthesia.

The serotoninergic receptor channel $\left(5-\mathrm{HT}_{3}\right.$ type) is 
expressed in the peripheral nerve and area postrema, where it plays a role in antinociception and antiemetic responses. Drugs targeting this channel, such as ondansetron and tropisetron, are in use as antiemetics. Glutamate receptor channels are instead important targets for neuroprotective and antiepileptic drugs, and thereby are used in the neuronal channelopathies. Drugs acting on glutamate receptors reduce the excitotoxicity in the CNS, being effective in acute hypoxic-ischemic brain injury and in chronic neurodegenerative diseases such as Alzheimer's, Parkinson's, Huntington's, and amyotrophic lateral sclerosis. Glutamate antagonists are also effective in neuropathic pain, dementia, and melanoma, as well as in neuroprotection. More recently, the use of glutamate agonists in schizophrenia has been proposed.

\section{CONCLUSION}

In this review, we sought to describe the pharmacology of ion channels involved in neurologic disorders with a special regard to neurologic channelopathies. Many other channels have been excluded from the review because their function or pharmacology are not noticeably related to neurologic diseases (e.g., the cystic fibrosis transmembrane conductance regulator chloride channel CFTR). Other channels have not been discussed here because their pharmacology, although very promising, is quite distant from therapeutic applications (e.g., the transient receptor potential channel TRP). Also non-neurologic channelopathies were not covered in detail, such as the cardiac arrhythmias (e.g., long QT and Brugada syndromes), kidney diseases (e.g., Dent's disease, Bartter's syndrome), and neonatal diabetes. It should be mentioned, however, that the reader will find excellent descriptions in the literature of these channelopathies and their treatment, which may serve as a paradigm for possible therapeutic approaches in the treatment of ion channelopathies.

Recent advances in genetic medicine, especially in ion channelopathies, have increased tremendously our knowledge of the physiopathological processes leading to neurologic disorders. In many cases, this knowledge has confirmed the validity of empirically used drugs targeting ion channels, such as the sodium channel blockers and the $\mathrm{GABA}_{\mathrm{A}} \mathrm{R}$ agonists in epilepsy. As in the case of ACTZ, a novel mechanism of action of an empiric drugs is being uncovered because of our understanding of the drug-responsive channelopathies. Moreover, other ion channels have been pinpointed as new candidate targets for drug therapy, such as the KCNQ potassium channels with retigabine currently in a phase III clinical trial evaluation for partial epilepsies. Specifically in the channelopathies, the fine dissection of the biophysical effects of mutations may help to pursue a pharmacogenetic approach aimed at defining the best drug for each individual.

Today, the gold standard technology for studying ion channel pharmacology remains the patch-clamp technique. The excellent signal and time resolutions of patch-clamp recordings allow the fine dissection of intimate drug-channel interactions. The downside is that this is a laborious and time-consuming procedure, which limits its application as a screening platform. With the increasing awareness of the importance of ion channels in drug discovery, owing in part to the understanding of channelopathies, high-throughput screening technologies are being developed in the pharmaceutical industry. On the other hand, application of genomics and proteomics to ion channels (i.e., channelomics) offers a tremendous opportunity to underscore the role of ion channels in many diseases and their contribution to the success or failure of pharmacological therapy.

It is thus likely that with a greater understanding of channel genetics, structure, and function, together with the identification of novel primary and secondary channelopathies, ion channel drugs will continue to see a substantial growth the neurologic pharmaceutical sector.

Acknowledgments: This work on ion channelopathies was supported by grants from Telethon-Italy (Grant no. GGP04140), the Italian "Ministero dell'Istruzione, dell'Università e della Ricerca" (Grants no. FIRBRBNE01XMP4 and PRIN-2005059597), and the Italian Space Agency (Project OSMA).

\section{REFERENCES}

1. Ruetsch YA, Böni T, Borgeat A. From cocaine to ropivacaine: the history of local anesthetic drugs. Curr Top Med Chem 2001;1:175182 .

2. Gutman GA, Chandy KG, Grissmer S, et al. International Union of Pharmacology. LIII. Nomenclature and molecular relationships of voltage-gated potassium channels. Pharmacol Rev 2005;57:473508 .

3. Dodson PD, Forsythe ID. Presynaptic $\mathrm{K}^{+}$channels: electrifying regulators of synaptic terminal excitability. Trends Neurosci 2004; 27:210-217.

4. Lehmann-Horn F, Lerche H, Jurkat-Rott K. Skeletal muscle channelopathies: myotonias, periodic paralyses and malignant hyperthermia. In: Stålberg E, editor. Clinical neurophysiology of disorders of muscle and neuromuscular junction, including fatigue. Handbook of Clinical Neurophysiology 2. Boston: Elsevier Science; 2003:457-483.

5. Vedeler CA, Antoine JC, Giometto B, et al. Management of paraneoplastic neurological syndromes: report of an EFNS Task Force. Eur J Neurol 2006;13:682-690.

6. Coghlan MJ, Carroll WA, Gopalakrishnan M. Recent developments in the biology and medicinal chemistry of potassium channel modulators: update from a decade of progress. J Med Chem 2001; 44:1627-1653.

7. Munoz-Caro C, Nino A. The nature of the receptor site for the reversible $\mathrm{K}^{+}$channel blocking by aminopyridines. Biophys Chem 2002;96:1-14.

8. Weisz CJ, Raike RS, Soria-Jasso LE, Hess EJ. Potassium channel blockers inhibit the triggers of attacks in the calcium channel mouse mutant tottering. J Neurosci 2005;25:4141-4145.

9. Skeie GO, Apostolski S, Evoli A, et al. Guidelines for the treat- 
ment of autoimmune neuromuscular transmission disorders. Eur J Neurol 2006;13:691-699.

10. Michelakis E. Anorectic drugs and vascular disease: the role of voltage-gated $\mathrm{K}^{+}$channels. Vascul Pharmacol 2002;38:51-59.

11. Tricarico D, Barbieri M, Mele A, Carbonara G, Conte Camerino D. Carbonic anhydrase inhibitors are specific openers of skeletal muscle BK channel of $\mathrm{K}^{+}$-deficient rats. FASEB J 2004;18:760-761.

12. Rogawski MA. Diverse mechanisms of antiepileptic drugs in the development pipeline. Epilepsy Res 2006;69:273-294.

13. Ashcroft FM. From molecule to malady. Nature 2006;440:440447.

14. Peretz A, Degani N, Nachman R. Meclofenamic acid and diclofenac, novel templates of KCNQ2/Q3 potassium channel openers, depress cortical neuron activity and exhibit anticonvulsant properties. Mol Pharmacol 2005;67:1053-1066.

15. Korsgaard MPG, Hartz BP, Brown WD, Ahring PK, Strøbæk D, Mirza NR. Anxiolytic effects of Maxipost (BMS-204352) and retigabine via activation of neuronal Kv7 channels. J Pharmacol Exp Ther 2005;314:282-292.

16. Wei AD, Gutman GA, Aldrich R, Chandy KG, Grissmer S, Wulff H. International Union of Pharmacology. LII. Nomenclature and molecular relationships of calcium-activated potassium channels. Pharmacol Rev 2005;57:463-472.

17. Ghatta S, Nimmagadda D, Xu X, O'Rourke ST. Large-conductance, calcium-activated potassium channels: structural and functional implications. Pharmacol Ther 2006;110:103-116.

18. Tricarico D, Mele A, Conte Camerino D. Carbonic anhydrase inhibitors ameliorate the symptoms of hypokalaemic periodic paralysis in rats by opening the muscular $\mathrm{Ca}^{2+}$-activated- $\mathrm{K}^{+}$channels. Neuromuscul Disord 2006;16:39-45.

19. Tricarico D, Mele A, Conte Camerino D. Phenotype-dependent functional and pharmacological properties of BK channels in skeletal muscle: effects of microgravity. Neurobiol Dis 2005;20:296302.

20. Szewczyk A, Skalska J, Glab M, et al. Mitochondrial potassium channels: from pharmacology to function. Biochim Biophys Acta 2006;1757:715-720.

21. Leniger T, Wiemann M, Bingmann D, Widman G, Hufnagel A, Bonnet U. Carbonic anhydrase inhibitor sulthiame reduces intracellular $\mathrm{pH}$ and epileptiform activity of hippocampal CA3 neurones. Epilepsia 2002;43:469-474.

22. Kubo Y, Adelman JP, Clapham DE, et al. International Union of Pharmacology. LIV. Nomenclature and structure-function relationships of inwardly rectifying potassium channels. Pharmacol Rev 2005;57:509-526.

23. Mannhold R. $\mathrm{K}_{\text {ATP }}$ channel openers: structure-activity relationships and therapeutic potentials. Med Res Rev 2004;24:213-266.

24. Ligtenberg JJ, Van Haeften TW, Van Der Kolk LE, et al. Normal insulin release during sustained hyperglycaemia in hypokalaemic periodic paralysis: role of the potassium channel opener pinacidil in impaired muscle strength. Clin Sci (Lond) 1996;91:583-589.

25. Wu L, Shen F, Lin L, Zhang X, Bruce IC, Xia Q. The neuroprotection conferred by activating the mitochondrial ATP-sensitive $\mathrm{K}^{+}$channel is mediated by inhibiting the mitochondrial permeability transition pore. Neurosci Lett 2006;402:184-189.

26. Tricarico D, Barbieri M, Laghezza A, Tortorella P, Loiodice F, Conte Camerino D. Dualistic actions of cromakalim and new potent $2 \mathrm{H}$-1,4-benzoxazine derivatives on the native skeletal muscle $\mathrm{K}_{\text {ATP }}$ channel. Br J Pharmacol 2003;139:255-262.

27. Tricarico D, Mele A, Lundquist AL, Desai RR, George AL Jr, Conte Camerino D. Hybrid assemblies of ATP-sensitive $\mathrm{K}^{+}$channels determine their muscle-type-dependent biophysical and pharmacological properties. Proc Natl Acad Sci U S A 2006;103:11181123.

28. Lesage F. Pharmacology of neuronal background potassium channels. Neuropharmacology 2003;44:1-7.

29. Catteral WA, Perez-Reyes E, Snutch TP, Striessnig J. International Union of Pharmacology. XLVIII. Nomenclature and structurefunction relationships of voltage-gated calcium channels. Pharmacol Rev 2005;57:411-425.

30. Spacey SD, Hildebrand ME, Materek LA, Bird TD, Snutch TP. Functional implications of a novel EA2 mutation in the P/Q-type calcium channel. Ann Neurol 2004;56:213-220.
31. McNaughton NCL, Davies CH, Randall A. Inhibition of $\alpha_{1 \mathrm{E}} \mathrm{Ca}^{2+}$ channels by carbonic anhydrase inhibitors. J Pharmacol Sci 2004; 95:240-247.

32. Cannon SC, Corey DP. Loss of $\mathrm{Na}^{+}$channel inactivation by anemone toxin (ATX II) mimics the myotonic state in hyperkalaemic periodic paralysis. J Physiol 1993;466:501-520.

33. Desaphy JF, Conte Camerino D, Franchini C, Lentini G, Tortorella $\mathrm{V}$, De Luca A. Increased hindrance on the chiral carbon atom of mexiletine enhances the block of rat skeletal muscle $\mathrm{Na}^{+}$channels in a model of myotonia induced by ATX. Br J Pharmacol 1999; 128:1165-1174.

34. Clare JJ, Tate SN, Nobbs M, Romanos MA. Voltage-gated sodium channels as therapeutic targets. Drug Discov Today 2000;5:506520.

35. Glaaser IW, Clancy CE. Cardiac $\mathrm{Na}^{+}$channels as therapeutic targets for antiarrhythmic agents. Handb Exp Pharmacol 2006;171: 99-121.

36. Yarov-Yarovoy V, McPhee JC, Idsvoog D, Pate C, Scheuer T, Catterall WA. Role of amino acid residues in transmembrane segments IS6 and IIS6 of the $\mathrm{Na}^{+}$channel $\alpha$ subunit in voltagedependent gating and drug block. J Biol Chem 2002;277:3539335401 .

37. Hille B. Ion channels of excitable membranes. 3rd ed. Sunderland, MA: Sinauer Associates; 2001.

38. Heatwole C, Moxley RT III. The nondystrophic myotonias. Neurotherapeutics 2007;4:238-251.

39. Trip J, Drost G, van Engelen BG, Faber CG. Drug treatment for myotonia. Cochrane Database Syst Rev 2006;1:CD004762.

40. Weckbecker K, Wurz A, Mohammadi B, et al. Different effects of mexiletine on two mutant sodium channels causing paramyotonia congenita and hyperkalemic periodic paralysis. Neuromuscul Disord 2000;10:31-39.

41. Desaphy J-F, De Luca A, Tortorella P, De Vito D, George AL Jr, Conte Camerino D. Gating of myotonic Na channel mutants defines the response to mexiletine and a potent derivative. Neurology 2001;57:1849-1857.

42. Takahashi MP, Cannon SC. Mexiletine block of disease-associated mutations in $\mathrm{S} 6$ segments of the human skeletal muscle $\mathrm{Na}^{+}$channel. J Physiol 2001;537:701-714.

43. Desaphy J-F, De Luca A, Didonna MP, George AL Jr, Conte Camerino D. Different flecainide sensitivity of hNav1.4 channels and myotonic mutants explained by state-dependent block. J Physiol 2004;554:321-334.

44. Berkovic SF. Influence of molecular genetic advances on therapy for the idiopathic epilepsies. Neurotherapeutics 2007 (in press).

45. Heron SE, Scheffer IE, Berkovic SF, et al. Channelopathies in idiopathic epilepsy. Neurotherapeutics 2007;4:295-304.

46. Lucas PT, Meadows LS, Nicholls J, Ragsdale DS. An epilepsy mutation in the $\beta 1$ subunit of the voltage-gated sodium channel results in reduced channel sensitivity to phenytoin. Epilepsy Res 2005;64:77-84.

47. Tate SK, Depondt C, Sisodiya SM, et al. Genetic predictors of the maximum doses patients receive during clinical use of the antiepileptic drugs carbamazepine and phenytoin. Proc Natl Acad Sci U S A 2005;102:5507-5512.

48. Legroux-Crespel E, Sassolas B, Guillet G, Kupfer I, Dupre D, Misery L. Treatment of familial erythermalgia with the association of lidocaine and mexiletine [In French]. Ann Dermatol Venereol 2003;130:429-433.

49. Waxman SG, Dib-Hajj S. Erythermalgia: molecular basis for an inherited pain syndrome. Trends Mol Med 2005;11:555-562.

50. Waxman SG, Hains BC. Fire and phantoms after spinal cord injury: $\mathrm{Na}^{+}$channels and central pain. Trends Neurosci 2006;29: 207-215.

51. Lai J, Porreca F, Hunter JC, Gold MS. Voltage-gated sodium channels and hyperalgesia. Annu Rev Pharmacol Toxicol 2004;44: 371-397.

52. Nassar MA, Baker MD, Levato A, et al. Nerve injury induces robust allodynia and ectopic discharges in Nav1.3 null mutant mice. Mol Pain 2006;2:33.

53. Sindrup SH, Jensen TS. Are sodium channel blockers useless in peripheral neuropathic pain? [Editorial]. Pain 2006 Oct. 17 [Epub ahead of print] 
54. Wang GK, Russell C, Wang SY. State-dependent block of voltagegated $\mathrm{Na}^{+}$channels by amitriptyline via the local anesthetic receptor and its implication for neuropathic pain. Pain 2004;110: $166-174$

55. Meola G, Sansone V. Treatment in myotonia and periodic paralysis. Rev Neurol (Paris) 2004;160:S55-S69.

56. Hemmings HC Jr. Neuroprotection by $\mathrm{Na}^{+}$channel blockade. J Neurosurg Anesthesiol 2004;16:100-101.

57. Lenkey N, Karoly R, Kiss JP, Szasz BK, Vizi ES, Mike A. The mechanism of activity-dependent sodium channel inhibition by the antidepressants fluoxetine and desipramine. Mol Pharmacol 2006; 70:2052-2063.

58. Wallace CH, Baczko I, Jones L, Fercho M, Light PE. Inhibition of cardiac voltage-gated sodium channels by grape polyphenols. $\mathrm{Br} \mathrm{J}$ Pharmacol 2006;149:657-665.

59. Desaphy JF, Pierno S, De Luca A, Didonna P, Conte Camerino D. Different ability of clenbuterol and salbutamol to block sodium channels predicts their therapeutic use in muscle excitability disorders. Mol Pharmacol 2003;63:659-670.

60. Bezzina CR, Tan HL. Pharmacological rescue of mutant ion channels. Cardiovasc Res 2002;55:229-232.

61. Jentsch TJ, Poet M, Fuhrmann JC, Zdebik AA. Physiological functions of $\mathrm{CLC} \mathrm{Cl}^{-}$channels gleaned from human genetic disease and mouse models. Annu Rev Physiol 2005;67:779-807.

62. Pusch M, Liantonio A, De Luca A, Conte Camerino D. Pharmacology of CLC chloride channels and transporters. In: Pusch M, editor. Chloride movements across cellular membranes. Advances in Molecular and Cell Biology 38. Amsterdam: Elsevier; 2007:83-107.

63. Cuppoletti J, Malinowska DH, Tewari KP, et al. SPI-0211 activates T84 cell chloride transport and recombinant human $\mathrm{ClC}-2$ chloride currents. Am J Physiol Cell Physiol 2004;287:C1173C1183.

64. De Luca A, Pierno S, Liantonio A, Camerino C, Conte Camerino D. Phosphorylation and IGF-1-mediated dephosphorylation pathways control the activity and the pharmacological properties of skeletal muscle chloride channels. Br J Pharmacol 1998;125:477482.

65. Conte Camerino D, Tricarico D, Pierno S, et al. Taurine and skeletal muscle disorders. Neurochem Res 2004;29:135-142.

66. Eguchi H, Tsujino A, Kaibara M, et al. Acetazolamide acts directly on the human skeletal muscle chloride channel. Muscle Nerve 2006;34:292-297.

67. Desaphy J-F, Rolland J-F, Valente EM, LoMonaco M, Conte Camerino D. Functional alteration of $\mathrm{ClC}-1$ channel mutants associated with transient weakness in myotonia congenita [Abstract 1291-Pos]. Biophys J 2007 [Epub in advance of print].

68. Bowery NG, Smart TG. GABA and glycine as neurotransmitters: a brief history. Br J Pharmacol 2006;147:S109-S119.

69. Cascio M. Modulating inhibitory ligand-gated ion channels. AAPS J 2006;8:E353-E361. 